\title{
NANOG PRIMING BEFORE FULL REPROGRAMMING MAY GENERATE GERM CELL TUMOURS
}

\author{
I. Grad ${ }^{1,2,}$, Y. Hibaoui ${ }^{1, \S}$, M. Jaconi ${ }^{3}$, L. Chicha 4 , R. Bergström-Tengzelius ${ }^{5}$, M.R. Sailani ${ }^{6}$, M.F. Pelte ${ }^{3}$, S. Dahoun ${ }^{6}$, \\ T.A. Mitsiadis ${ }^{7}$, V. Töhönen ${ }^{8}$, S. Bouillaguet ${ }^{2}$, S.E. Antonarakis ${ }^{6}$, J. Kere ${ }^{8}$, \\ M. Zucchelli ${ }^{8, \S \S}$, O. Hovatta ${ }^{5, \S}$ and A. Feki ${ }^{1, *}$ \\ ${ }^{1}$ Department of Obstetrics and Gynaecology, Geneva University Hospitals, Geneva, Switzerland \\ ${ }^{2}$ Section of Dental Medicine, University of Geneva, Geneva, Switzerland \\ ${ }^{3}$ Department of Pathology and Immunology, University of Geneva Medical School, Geneva, Switzerland \\ ${ }^{4}$ CNS Research Department, Hoffmann-LaRoche, Basel, Switzerland \\ ${ }^{5}$ Division of Obstetrics and Gynaecology, Department of Clinical Science, Intervention and Technology, Karolinska \\ Institutet, Huddinge, Sweden \\ ${ }^{6}$ Department of Genetic Medicine and Development, University of Geneva Medical School, Geneva, Switzerland \\ ${ }^{7}$ Institute of Oral Biology, Faculty of Medicine, University of Zurich, Zurich, Switzerland \\ ${ }^{8}$ Department of Biosciences and Nutrition, Karolinska Institutet, Huddinge, Sweden \\ $\S \S$ These authors contributed equally to the paper
}

\begin{abstract}
Reprogramming somatic cells into a pluripotent state brings patient-tailored, ethical controversy-free cellular therapy closer to reality. However, stem cells and cancer cells share many common characteristics; therefore, it is crucial to be able to discriminate between them. We generated two induced pluripotent stem cell (iPSC) lines, with NANOG pre-transduction followed by OCT3/4, SOX2, and LIN28 overexpression. One of the cell lines, CHiPS W, showed normal pluripotent stem cell characteristics, while the other, CHiPS A, though expressing pluripotency markers, failed to differentiate and gave rise to germ cell-like tumours in vivo. Comparative genomic hybridisation analysis of the generated iPS lines revealed that they were genetically more stable than human embryonic stem cell counterparts. This analysis proved to be predictive for the differentiation potential of analysed cells. Moreover, the CHiPS A line expressed a lower ratio of $\mathrm{p} 53 / \mathrm{p} 21$ when compared to CHiPS W. NANOG pre-induction followed by OCT3/4, SOX2, MYC, and KLF4 induction resulted in the same tumour-inducing phenotype. These results underline the importance of a re-examination of the role of NANOG during reprogramming. Moreover, this reprogramming method may provide insights into primordial cell tumour formation and cancer stem cell transformation.
\end{abstract}

Keywords: Induced pluripotent stem cells, stem cells, cancer stem cells, NANOG, cancer, germ-cell tumour, reprogramming, pluripotency.

*Address for correspondence:

Anis Feki

Médecin chef / Chefarzt

Service de gynécologie obstétrique

HFR Fribourg - Hôpital cantonal

Chemin des Pensionnats 2-6

Case postale

1708 Fribourg, Switzerland

Telephone Number: +41264267355

FAX Number: +41264267367

E-mail: fekia@h-fr.ch

\section{Introduction}

Pluripotent stem cells have attracted much attention from the scientific community in recent years. They hold promise for various therapeutic applications, from regenerative therapies to pharmacological screening. Technical difficulties and ethical issues associated with the isolation of adult or embryonic stem cells have redirected interest towards induced pluripotent stem cells (iPSCs). Obtained from lineage-specific cells via reprogramming with a maximum of four reprogramming genes (RGs), POU5F1 (OCT3/4), SOX2 and MYC, KLF4, or NANOG and LIN28 (Takahashi et al., 2007; Yu et al., 2007), iPSCs seem to be a very promising area for future stem cell research. Despite obvious advantages such as donor compatibility and an unlimited supply, there are still numerous challenges to be met before iPSCs become routinely used in regenerative medicine or standardised for patient-specific drug research (reviewed in: Stadtfeld and Hochedlinger, 2010). One major obstacle is the capability of pluripotent stem cells to form tumours in vivo. At first, human embryonic stem cells (hESC) were believed to produce only benign teratomas; however, recent studies have demonstrated that hESC lines can also develop malignant features after being kept in culture (Hovatta et al., 2010; reviewed in: Blum and Benvenisty, 2009).

There is increasing evidence of the existence of a distinct cell sub-population within a tumour, called cancer stem cells (CSCs), which shares many characteristics with normal stem cells (Bonnet and Dick, 1997). CSCs are believed to be responsible for the tumour's ability to undergo epithelial-mesenchymal transition (EMT), and may play a role in relapse, metastasis, and treatment resistance (reviewed in: Bomken et al., 2010; Tysnes, 2010). It remains controversial as to whether CSCs originate from stem cells that have undergone aberrant transformation or from terminally differentiated cells that have reversed their cellular program. Very limited evidence indicates that normal stem cells and cancer stem cells differ (Guzman et al., 2005; Yilmaz et al., 2006). Therefore, it is crucial to understand the carcinogenic aspect of stem cells before they can be implemented 
therapeutically. Thus, research towards finding ways to limit the tumour formation risk of iPSC, for instance by developing strategies allowing accurate sorting of potentially carcinogenic cells, is essential. In the present study, we generated and analysed two iPSC lines. One of the lines, the CHiPS W, displayed normal pluripotent stem cell characteristics and gave rise to a teratoma expressing components of the three germ layers during an in vivo differentiation assay. The other line, the CHiPS A, despite its iPSC-like morphology and marker expression, resulted in germ cell-like tumours when injected into immunoincompetent mice. The analysis of OCT3/4 and NANOG expression and the methylation status of their promoters showed their re-activation in the CHiPS A line. Since it has been previously demonstrated that genomic instability in hESC lines might lead to neoplastic progression (Werbowetski-Ogilvie et al., 2009), we used comparative genomic hybridisation and single nucleotide polymorphism assays to detect genomic signatures in the derived iPSC lines. We also estimated the relative expression of TP53 (p53) and CDKN1A (p21) in both lines. Finally, we showed that the resulting NANOG-induced tumourigenic phenotype is independent of the other RGs used. These results underline the importance of a reexamination of the role of NANOG during reprogramming and the need for detailed iPSC characterisation prior to clinical use. Moreover, as the generated lines were derived from a uniform genetic background, they may serve as a model of cancer stem cell formation.

\section{Materials and Methods}

\section{Cell lines}

The hESC line H1 came from the WiCell Research Institute (Madison, WI, USA). HS401 was derived as previously described (Inzunza et al. 2005; Ström et al., 2010). iPSC lines were derived as follows: the CHiPS A line was derived by transducing 50,000 human fibroblasts (ATCC, CRL2429) with 5 MOI of pSin-EF2-Nanog-Pur. After 24 h, cells were re-transduced with three viruses (MOI 5): pSin-EF2Sox2-Pur, pSin-EF2-Oct4-Pur, and pSin-EF2-Lin28-Pur (kindly donated by J.A. Thomson). The CHiPS W line was derived by transducing 50,000 human fibroblasts with 5 MOI of pSin-EF2-Nanog-Pur. The cells were treated with puromycin for 5 days to select for transformed cells and then re-transduced with three viruses: pSin-EF2-Sox2-Pur, pSin-EF2-Oct4-Pur, and pSin-EF2-Lin28-Pur (MOI 5). The CHiPS 22 line was derived by first transducing 50,000 human fibroblasts with 5 MOI of pSin-EF2-Nanog-Pur; after $24 \mathrm{~h}$, cells were re-transduced with the Stem Cell Cassette (STEMCCA) polycistronic lentiviral vector, carrying the four Yamanaka RGs (Sommer et al., 2009) (kindly donated by G. Mostoslavsky). All iPSC and hESC lines were cultured on irradiated human foreskin fibroblasts and passaged mechanically. Cells were grown in iPSC medium: Knockout Dulbecco's Minimal Essential Medium (DMEM) supplemented with $20 \%$ Serum Replacement, 2 $\mathrm{mmol} / \mathrm{L}$ Glutamax, $40 \mu \mathrm{g} / \mathrm{mL}$ gentamycin and $100 \mu \mathrm{mol} / \mathrm{L}$ $\beta$-mercaptoethanol (all Gibco/Invitrogen, Carlsbad, CA, USA). For the H1 cell line, medium was supplemented with $10 \mathrm{ng} / \mathrm{mL}$ bFGF (fibroblast growth factor). All iPSC lines were initially cultured according to the protocol established by Thomson's group (Yu et al., 2007), and supplemented with $100 \mathrm{ng} / \mathrm{mL}$ bFGF; however, the CHiPS 22 and CHiPS A lines grew robustly, so we decided to lower the concentration of bFGF to $10 \mathrm{ng} / \mathrm{mL}$ for those lines to decrease the cost of culture. To exclude the influence of the different bFGF concentrations on the experimental results, prior to DNA, RNA or protein extraction, cells were cultured for one passage (at least $48 \mathrm{~h}$ ) under feeder-free culture conditions on Matrigel (Becton Dickinson AG, Basel, Switzerland) coated plates in NutriStem medium (Stemgent, Cambridge, MA, USA) supplemented with 10 ng/mL bFGF. Matrigel was diluted 1:30 with KO DMEM and after plating allowed to gel at room temperature for 1 $\mathrm{h}$ before use. The fibroblast feeders (ATCC, Manassas, VA, USA; CRL-2429) were cultured in IMDM supplemented with $10 \%$ foetal calf serum, $2 \mathrm{mmol} / \mathrm{L}$ Glutamax and 1 $\%$ penicillin/streptomycin (all Gibco/Invitrogen). Feeder cells were mitotically inactivated by irradiation at $35 \mathrm{~Gy}$ before seeding on a gelatin-coated $35 \mathrm{~mm}$ dish at $3.5 \times 10^{5}$ cells/dish. The iPSC and hESC culture medium was changed daily.

\section{Immunohistochemistry}

Cells were passaged manually onto a GFP-positive feeder layer (Unger et al., 2009). After fixation in 4 $\%$ formaldehyde, they were washed three times with phosphate buffered saline (PBS), blocked with $1 \%$ bovine serum albumin (BSA) and stained with antibodies against OCT3/4 (Santa Cruz Laboratories, Santa Cruz, CA, USA; sc-5279), NANOG (Santa Cruz Laboratories, sc-33759), TRA-1-60 (Santa Cruz Laboratories, sc21705), and SSEA4 (Santa Cruz Laboratories, sc-21704) overnight at $4{ }^{\circ} \mathrm{C}$. After three washes with PBS, cells were incubated with fluorescent probe-labelled secondary antibodies and mounted with UltraCruz ${ }^{\mathrm{TM}}$ Mounting Medium containing DAPI. Ki-67 immunostaining was performed as follows: after standard deparaffinisation, antigen retrieval was performed with $0.01 \mathrm{M}$ citrate $(\mathrm{pH}$ 6) at $100{ }^{\circ} \mathrm{C}$. Endogenous peroxidase was blocked with HP-Blocking solution (S2023; Dako, Glostrup, Denmark) and the slides were incubated with a Ki-67 antibody (mib1, Dako, M7240). Secondary antibody incubation and signal development was performed in DAB solution according to the manufacturer's instruction (Dako). All staining were performed three times independently.

\section{Karyotype}

Karyotyping was performed in at least twenty metaphase spreads, using the GTG-banding method, by an independent laboratory (Genetic Service, Geneva University Hospitals, Switzerland). Briefly, iPSCs were incubated in iPSC medium, supplemented with $0.2 \mathrm{mg} / \mathrm{mL}$ colcemid (Roche, Basel, Switzerland) at $37^{\circ} \mathrm{C}$ for $20 \mathrm{~min}$, and subsequently washed three times with $2 \mathrm{~mL}$ PBS containing $\mathrm{Ca}^{2+}$ and $\mathrm{Mg}^{2+}$. A minimum of 15 colonies were collected in $2 \mathrm{~mL}$ $1 \times$ trypsin-EDTA (Invitrogen) and incubated at $37^{\circ} \mathrm{C}$ for $5 \mathrm{~min}$. The final mixture of cells was pipetted several times to disaggregate the cells. The trypsin activity was stopped with $4 \mathrm{~mL}$ iPSC medium and cells were spun at $300 \mathrm{~g}$ 
Table 1. Primers used in the study.

\begin{tabular}{|c|c|c|c|}
\hline \multicolumn{4}{|c|}{ quantitative PCR } \\
\hline Gene & Forward & Reverse & Amplicon \\
\hline GUSB & CCACCAGGGACCATCCAAT & AGTCAAAATATGTGTTCTGGACAAAGTAA & 79 \\
\hline $\begin{array}{l}\text { OCT3/4 } \\
\text { (POU5F1) }\end{array}$ & AGTGCCCGAAACCCACACTG & ACCACACTCGGACCACATCCT & 81 \\
\hline NANOG & GATTTGTGGGCCTGAAGAAA & TTGGGACTGGTGGAAGAATC & 138 \\
\hline LIN28 & TGTAAGTGGTTCAACGTGCG & ССТСАСССТССТTCAAGCTC & 145 \\
\hline SOX2 & GCGAACCATCTCTGTGGTCT & GGAAAGTTGGGATCGAACAA & 145 \\
\hline Brachyury & ACAGCTGTGACAGGTACCCAAC & CATGCAGGTGAGTTGTCAGAAT & 109 \\
\hline NKX2.5 & CTATCCACGTGCCTACAGCGAC & GCACAGCTCTTTCTTTTCGGC & 67 \\
\hline MSI & TTGGGAAGGTGGACGACG & CTCAAACGTGACAAACCCGAAC & 80 \\
\hline FOXA2 & GGAGCGGTGAAGATGGAAG & TACGTGTTCATGCCGTTCAT & 122 \\
\hline $\begin{array}{l}\text { REX1 } \\
\text { (ZFP42) }\end{array}$ & GAAGAGGCCTTCACTCTAGTAGTG & TTTCTGGTGTCTTGTCTTTGCCCG & 179 \\
\hline \multicolumn{4}{|c|}{ semi-quantitative PCR } \\
\hline Gene & Forward & Reverse & Amplicon \\
\hline $\begin{array}{l}\text { OCT3/4 } \\
\text { (POU5F1) } \\
\text { endogenous }\end{array}$ & GCCTTCCTTCCCCATGGC & CCTCAAAATCCTCTCGTTGT & 911 \\
\hline $\begin{array}{l}\text { OCT3/4 } \\
\text { (POU5F1) } \\
\text { exogenous }\end{array}$ & TCAAGCCTCAGACAGTGGTTC & CCTCAAAATCCTCTCGTTGT & 976 \\
\hline $\begin{array}{l}\text { NANOG } \\
\text { endogenous }\end{array}$ & TCСТCTATACTAACATGAGTG & AACACAGTTCTGGTCTTCTG & 319 \\
\hline $\begin{array}{l}\text { NANOG } \\
\text { exogenous }\end{array}$ & TCAAGCCTCAGACAGTGGTTC & AACACAGTTCTGGTCTTCTG & 385 \\
\hline GAPDH & AGCCACATCGCTCAGACACC & GTACTCAGCGGCCAGCATCG & 174 \\
\hline DAZL & ATGTTAGGATGGATGAAACTGAGATTA & CCATGGAAATTTATCTGTGATTCTACT & 178 \\
\hline GDF3 & AGACTTATGCTACGTAAAGGAGCT & CTTTGATGGCAGACAGGTTAAAGTA & 150 \\
\hline KIT & CAGGCAACGTTGACTATCAGT & ATTCTCAGACTTGGGATAATC & 288 \\
\hline STELLAR & GTTACTGGGCGGAGTTCGTA & TGAAGTGGCTTGGTGTCTTG & 174 \\
\hline SOX2 & F AGA TGC ACA ACT CGG AGA TC & GTC ATG GAG TTG TAC TGC AG & 438 \\
\hline $\begin{array}{l}\text { STEMCCA } \\
\text { OCT3/4 -KLF4 } \\
\text { JUNCTION }\end{array}$ & ACCATCTGTCGCTTCGAGGCC & GGCTAGGAGGGCCGGGTTGTT & 848 \\
\hline
\end{tabular}

for $10 \mathrm{~min}$. Subsequently, the pellet was resuspended and incubated in $1 \mathrm{~mL}$ pre-warmed potassium chloride solution $(\mathrm{KCl}, 0.075 \mathrm{M})$ for $10 \mathrm{~min}$ at $37^{\circ} \mathrm{C}$. Cells were then prefixed with $1 \mathrm{~mL}$ Carnoy fixative solution (methanol/acetic acid $=3 / 1$ ) at $-20{ }^{\circ} \mathrm{C}$, and immediately spun at $1800 \mathrm{rpm}$ for $10 \mathrm{~min}$. Finally, the supernatant was discarded, the pellet resuspended again in Carnoy fixative solution and the cells were prepared for analysis.

RNA extraction, quantitative and non-quantitative real time polymerase chain reaction

Total RNA was extracted from the cell lines, using the QIAGEN (Hilden, Germany) RNeasy MiniKit according to the manufacturer's protocol (Invitrogen). RNA integrity and quantity were assessed with an Agilent (Santa Clara, CA,
USA) 2100 bioanalyser, using RNA 6000 nanochips. $1 \mu \mathrm{g}$ of total RNAs were reverse transcribed with the Superscript III reverse transcriptase (Invitrogen) according to the manufacturer's protocol. One-twentieth cDNA template was used as template for each PCR reaction. cDNA was real time polymerase chain (PCR) amplified in a 7900HT Sequence Detection Systems (Applied Biosystems, Foster City, CA, USA) using the Power SYBR Green PCR master mix (Applied Biosystems). Raw threshold-cycle (Ct) values were obtained with the Sequence Detection Systems 2.0 software (Applied Biosystems). Melting curve analysis were automatically performed to monitor production of the appropriate PCR product. Relative quantities (RQs) were calculated with the formula $\mathrm{RQ}=\mathrm{E}-\mathrm{Ct}$, using efficiencies calculated for each run with the Data Analysis for Real- 
Time PCR (DART-PCR) algorithm, as described (Peirson et al., 2003). A mean quantity was calculated from triplicate PCR reactions for each sample, and this quantity was normalised to similarly measured quantity of normalisation gene (GusB). The highest normalised relative quantity was arbitrarily designated as a value of 1.0 and the other quantities were recalculated proportionally. Each PCR reaction was performed at least in triplicate with negative controls and the mean quantities were calculated from them. They were expressed as $+/-\mathrm{SD}$. For non-quantitative $\mathrm{PCR}$, reactions were performed in a Biometra (Göttingen, Germany) thermocycler, with RedTaq polymerase mix (Sigma-Aldrich, St. Louis, MO, USA), $250 \mathrm{nM}$ primers and $1 \mu \mathrm{L}$ of cDNA. In the case of teratoma RT-PCR, we used $3 \mu \mathrm{L}$ of template cDNA. Primers are listed in Table 1.

\section{Bisulphite sequencing}

About $2 \mu \mathrm{g}$ of DNA, extracted from the iPSC and control cell lines, were bisulphite-converted and purified using Epitect Bisulfite Kits (Qiagen) following the manufacturer's instructions. DNA bisulphite treatment and processing were performed simultaneously for all cell lines. The promoter regions of OCT4 and NANOG were amplified with specific primers as described previously (Freberg et al., 2007) using JumpStart REDTaq DNA Polymerase (Sigma-Aldrich) and KAPA2G Robust DNA Polymerase (Kapa Biosystems, Cambridge, MA, USA). Unincorporated primers and nucleotides were removed by incubation with Exonuclease I and Shrimp Alkaline Phosphatase (New England Biolabs, Ipswich, MA, USA), and the PCR products were cloned into the pCRII-TOPO vector (Invitrogen); transformants were grown on agar plates supplemented with X-Gal. Randomly chosen clones containing an insert were re-amplified by M13 primers and sequenced by SP 6 and T7 common primers from each cell line for each gene.

\section{Teratoma formation assay}

IPS cells were grown on Matrigel-coated dishes and collected by trypsin digestion. About $5 \times 10^{6}$ cells mixed with Matrigel (diluted in KO DMEM 5:1) were injected into the hind limb muscle of 8 -week-old Nod-SCID mice. Teratomas were dissected after 8-12 weeks and fixed in 4 $\%$ paraformaldehyde overnight. Samples were embedded in paraffin, cut, and stained with haematoxylin and eosin.

\section{Affymetrix SNP 6.0 array and DNA copy number variations}

Genotyping was carried out using the Affymetrix GenomeWide Human SNP Array 6.0 (San Diego, CA, USA). Labelling and hybridisation were performed following the protocols and kits provided by the manufacturer (Affymetrix Genome-Wide Human SNP Nsp/Sty Assay Kit 5.0/6.0). A set of 50 arrays previously hybridised and genotyped in the same laboratory was used as the copy number neutral reference sample. Copy-number variations (CNVs) and loss of heterozygosity (LOHs) were extracted with the Affymetrix proprietary Genotyping Console Software, using the standard setup recommended by the producer. Variations were annotated using the libraries supplied by Affymetrix (version 29). Copy number neutral
LOH regions (UPDs) were detected by determining $\mathrm{LOH}$ regions from the genotype calls (dChip, https://sites. google.com/site/dchipsoft/home, 2010) and by comparing the results with the ploidy detected in those regions by the Affymetrix software. Genes were annotated to detect variations using the Biomart database (http://www.biomart. org/, 2010). Gene ontology analysis was performed in $\mathrm{R}$ (www.r-project.org, 2010) using the package GO_stats ver. 2.12. The gene's universe was determined from the Affymetrix annotation files (version 29).

\section{In vitro differentiation of the pluripotent stem cells}

Whole iPSC and hESC colonies were dissected into ultra low attachment dishes (Corning Costar, Lowell, MA, USA) in KO DMEM medium supplemented with $10 \%$ NCS, $1 \mathrm{mM}$ L-glutamine, $100 \mu \mathrm{M}$ non-essential amino acids, $100 \mu \mathrm{M}$ 2-mercaptoethanol, $50 \mathrm{U} / \mathrm{mL}$ penicillin and $50 \mathrm{mg} / \mathrm{mL}$ streptomycin (Gibco/Invitrogen). Within $24 \mathrm{~h}$, cells aggregated to form embryoid bodies (EBs). Cardiac differentiation was performed using standard procedures, as previously described (Bettiol et al., 2006). Haematopoietic differentiation was carried out as recently described (Chicha et al., 2011). Briefly, collagenased colonies of iPSC were resuspended in StemPro-34 Serum-Free Media (Gibco/Invitrogen) supplemented with $0.5 \mathrm{ng} / \mathrm{mL}$ human recombinant BMP-4 (R\&D Systems, Minneapolis, MN, USA) in low cluster tissue culture dishes (Corning Costar, Lowell, MA, USA). At day 1 of differentiation, embryoid bodies (EBs) were harvested and transferred to fresh StemPro media supplemented with $10 \mathrm{ng} / \mathrm{mL}$ BMP-4 and $5 \mathrm{ng} / \mathrm{mL}$ bFGF. After $72 \mathrm{~h}$, EBs were harvested again and transferred to a haematopoietic medium consisting of StemPro media supplemented with $100 \mathrm{ng} / \mathrm{mL}$ human recombinant VEGF (R\&D Systems), $5 \mathrm{ng} / \mathrm{mL}$ bFGF, 100 ng/mL SCF (Amgen), 100 ng/mL FLT3-L (Amgen), and 40 ng/mL TPO (Peprotech, London, UK) for 4 additional days. All differentiation steps were performed under hypoxic conditions $\left(5 \% \mathrm{O}_{2}\right)$ in a humidified incubator at $37^{\circ} \mathrm{C}$.

\section{Flow cytometry}

Cell suspensions were analysed after staining with antibodies specific for CD34 and KDR (BD Biosciences, Allschwill, Switzerland). Dead cells were identified as 7-aminoactinomycin D (7AAD)-positive cells and were excluded. Cells were stained in PBS containing $20 \%$ human AB serum (Sigma-Aldrich) to prevent nonspecific binding. Data were collected using a FACS Calibur device (BD Biosciences) and analysed with Flowjo software (Treestar, Olten, Switzerland).

\section{Immunoblotting}

CHiPS A and CHiPS W cells were grown on Matrigelcoated dishes, trypsinised and counted. Protein extracts were prepared by lysing the cells in protein isolation buffer (10 mM Tris- $\mathrm{HCl} \mathrm{pH} 8,1 \%$ Triton-X100, 2 mM EDTA, $10 \%$ glycerol, $137 \mathrm{mM} \mathrm{NaCl}$, and a proteinase inhibitor cocktail) to a final concentration of about 300,000 cells per $15 \mu \mathrm{L}$. The lysates from 300,000 cells were resolved by SDS-polyacrylamide gel electrophoresis. For immunoblotting, the following antibodies were used: a p53-specific polyclonal antibody (Santa Cruz Laboratories, 


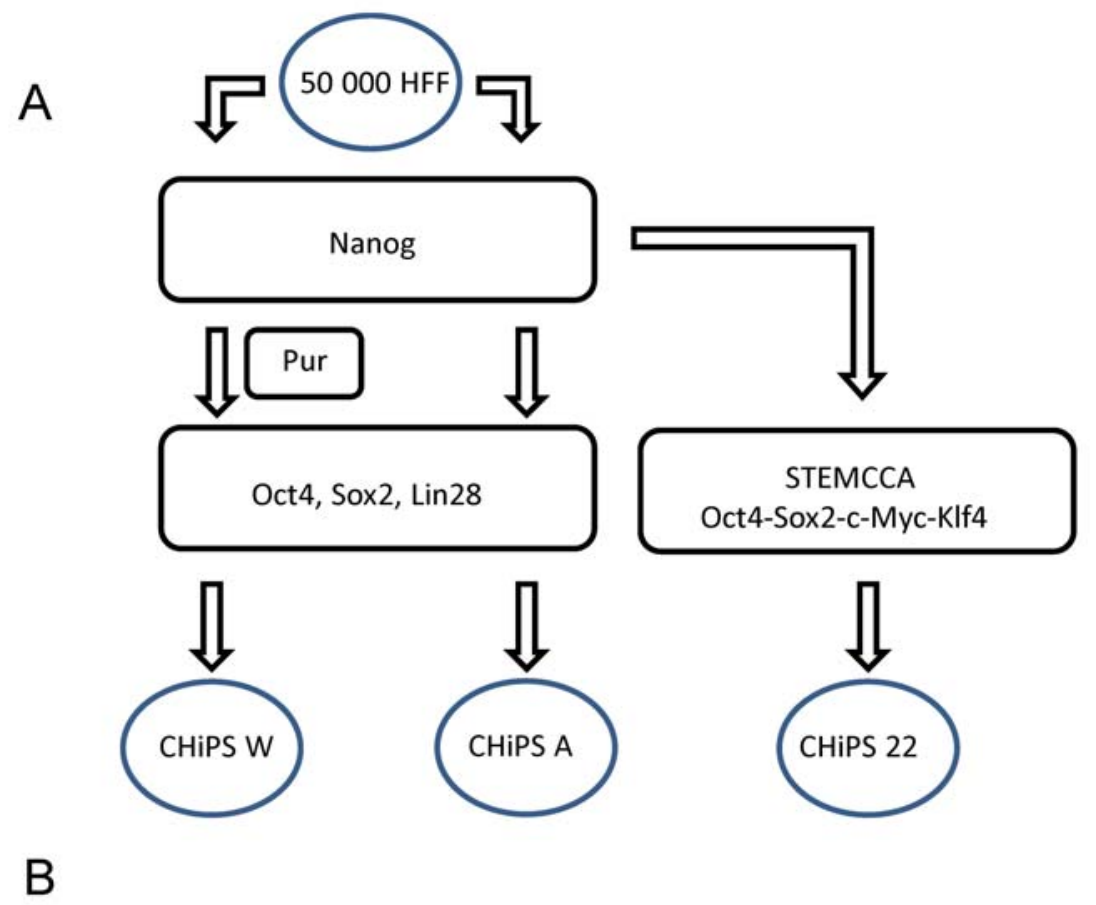

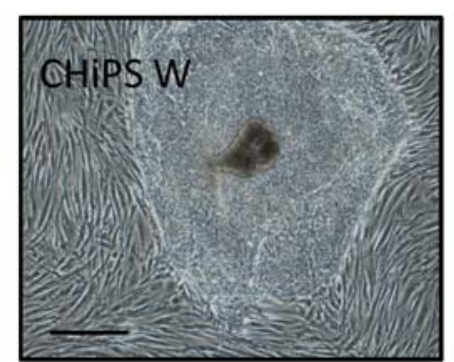

CHiPS W

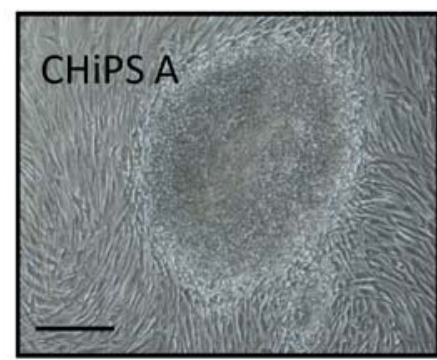

CHiPS A

c
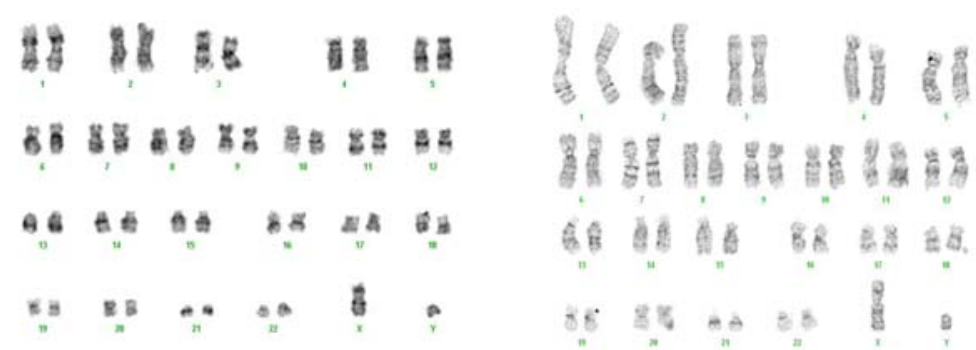

Fig. 1. Generation of induced pluripotent stem cell lines from human fibroblasts (A) Schematic representation of the reprogramming of the lines used in the study. Pur - puromycin. (B) Phase contrast images of the induced pluripotent stem cell lines CHiPS W and CHiPS A, growing on feeders. Scale bar $=300 \mu \mathrm{m}$. (C) CHiPS W and CHiPS A karyotype.

sc-126), and a monoclonal p21-specific antibody (Santa Cruz Laboratories, sc-397). The experiment was repeated three times independently.

\section{Results}

\section{Generation and characterisation of iPS cells from human fibroblasts}

It has been demonstrated that the introduction of four reprogramming factors (OCT3/4, SOX2, NANOG, and LIN28) into a somatic cell results in a return to the pluripotent state, albeit with low efficiency (Takahashi et al., 2007; Yu et al., 2007). Given that Nanog overexpression in mouse ESC increases reprogramming efficiency (Silva et al., 2006), and that re-induction of the reprogramming transgenes leads to higher iPSCs generation (Maherali et al., 2008), we wanted to check whether two-step reprogramming would increase the effectiveness of the process. Therefore, human fibroblasts were reprogrammed to pluripotency first by using only a NANOG-expressing lentiviral vector (Yu et al., 2007). After 24 h, one part of 


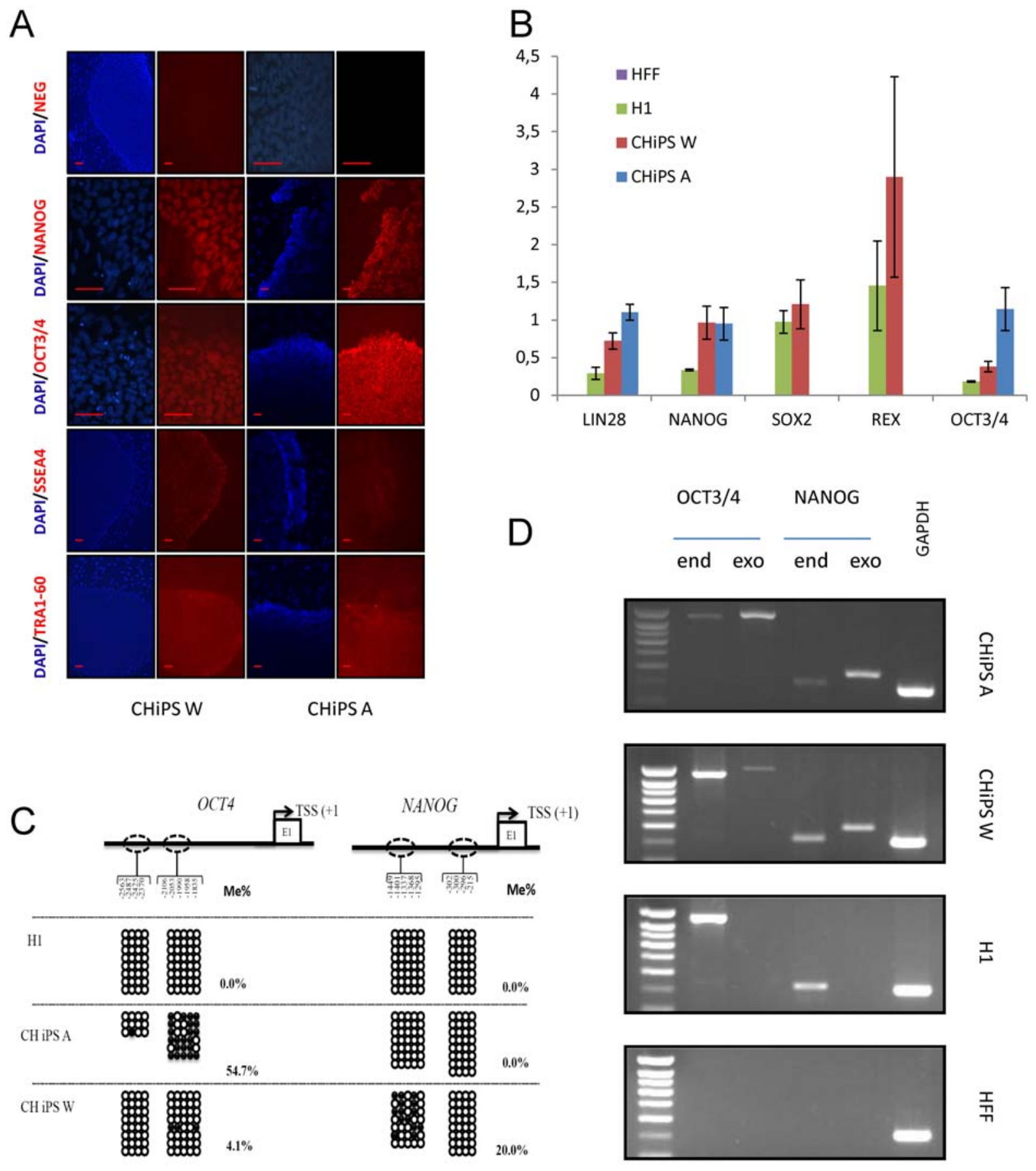

Fig. 2. Characterisation of CHiPS W and CHiPS A lines. (A) Immunohistochemistry of pluripotency markers NANOG, OCT3/4, SSEA4, TRA1-60 (red) and DAPI (blue). NEG-negative control. Scale bar $=20 \mu \mathrm{m}$. (B) qRT-PCR analysis of Lin28, NANOG, SOX2, REX1 and OCT3/4 expression in parental fibroblasts, the human embryonic stem cell line $\mathrm{H} 1$ and the induced pluripotent stem cell lines CHiPS W and CHiPS A. (C) Bisulphite genomic sequencing of OCT4 and NANOG promoters in the CHiPS A, CHiPS W and H1 lines. Each row represents an individual sequencing reaction for a given amplicon. Open and filled circles indicate unmethylated and methylated CpGs dinucleotides, respectively. The percentage of methylation for each cell line is shown on the right. (D) RT-PCR analysis of exogenous and endogenous OCT3/4 and NANOG transcripts. HFF - human feeder fibroblasts.

the cells were re-transduced with three separate lentiviral vectors overexpressing the transcription factors OCT3/4, SOX2, and LIN28 (Yu et al., 2007), resulting in the CHiPS A line (Fig. 1A). The other part of the cells was treated with puromycin for 5 days before re-transduction with the same lentivectors as the CHiPS A line, resulting in the CHiPS W line (Fig. 1A). After three weeks, reprogrammed colonies were manually selected based on morphological criteria and expanded. The selected clones had typical ESC morphology (Fig. 1B) and displayed a normal karyotype as assessed by metaphase spreads (Fig. 1C); however, the CHiPS A line proliferated significantly 


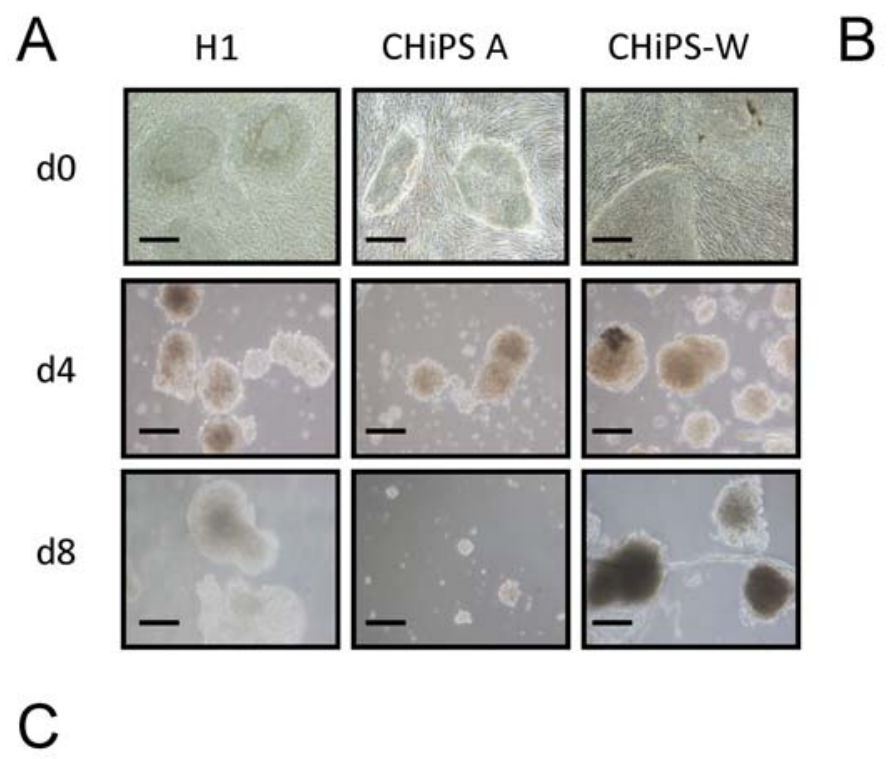

\section{CHiPS W}
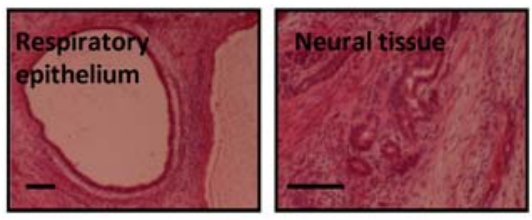

CHiPS A

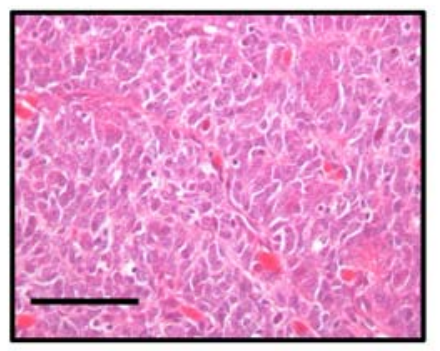

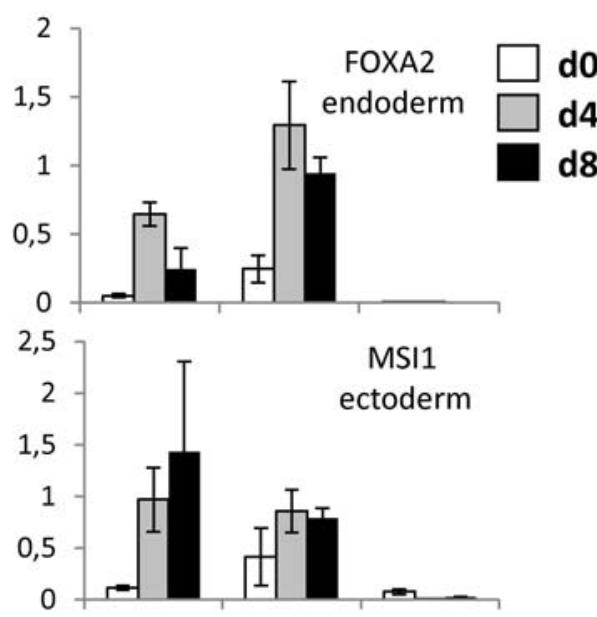

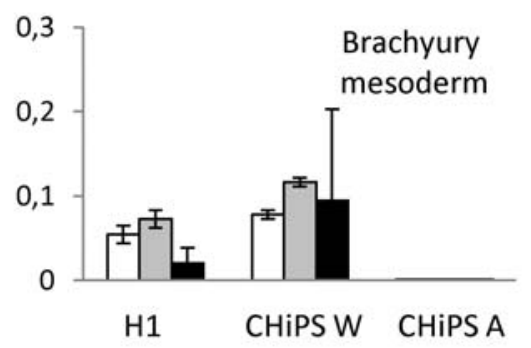

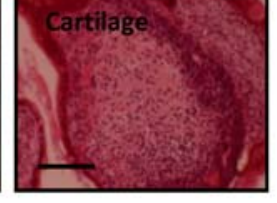

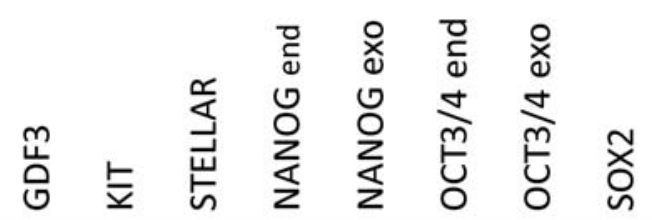

Fig. 3. In vitro and in vivo differentiation of CHiPS W and CHiPS A lines. (A) Phase contrast images of CHiPS A, CHiPS W and hESC H1 lines after spontaneous differentiation as embryoid bodies in suspension culture, at day 0 , 4 and 8. Scale bar $=300 \mu \mathrm{m}$. (B) Quantitative expression of three germ layer markers in CHiPS A, CHiPS W and H1 lines. (C) Haematoxylin and eosin staining of tumours derived from intramuscular injection of iPSCs in NODSCID mice. CHiPS W line formed teratoma with all embryonic germ layers mesoderm (cartilage) ectoderm (neural tissue) and endoderm (respiratory epithelium) whereas CHiPS A line formed germ cell-like tumour. The scale bar corresponds to $200 \mu \mathrm{m}$ for CHiPS W, $100 \mu \mathrm{m}$ for CHiPS A. (D) Expression of the seminoma (DAZL, GDF3, KIT, STELLAR) and the pluripotency (NANOG, OCT3/4) markers in CHiPS A-derived tumour by RT-PCR.

faster than the CHiPS W line (data not shown). The iPSC lines expressed the human ESC pluripotency antigens OCT3/4, NANOG, SSEA4 and TRA-1-60 as demonstrated by immunohistochemistry (Fig. 2A). We analysed the expression of pluripotency markers ZFP42 (REX1), SOX2, NANOG, LIN28, and OCT3/4 by quantitative PCR (Fig. 2B). The analysis showed that, contrary to the CHiPS W line, the CHiPS A line did not express SOX2 and REX1 but overexpressed OCT3/4 instead. In addition, the levels of LIN28 in the CHiPS A line were also higher than in the CHiPS W line. To clarify the origin of the transcript, we performed bisulphite sequencing, which revealed a surprising methylation status of the OCT3/4 and NANOG promoters in the CHiPS A and W lines (Fig. 2C). Despite overexpression of OCT3/4, the OCT3/4 promoter in the CHiPS A line was highly (55\%) methylated, while the NANOG promoter was demethylated. CHiPS W showed negligible methylation at the OCT3/4 promoter and moderate methylation at the NANOG promoter (Fig. $2 \mathrm{C})$. The results suggest a lack of retroviral silencing and therefore exogenous expression of OCT3/4 in the CHiPS A line. Semi-quantitative RT-PCR confirmed the predominant 

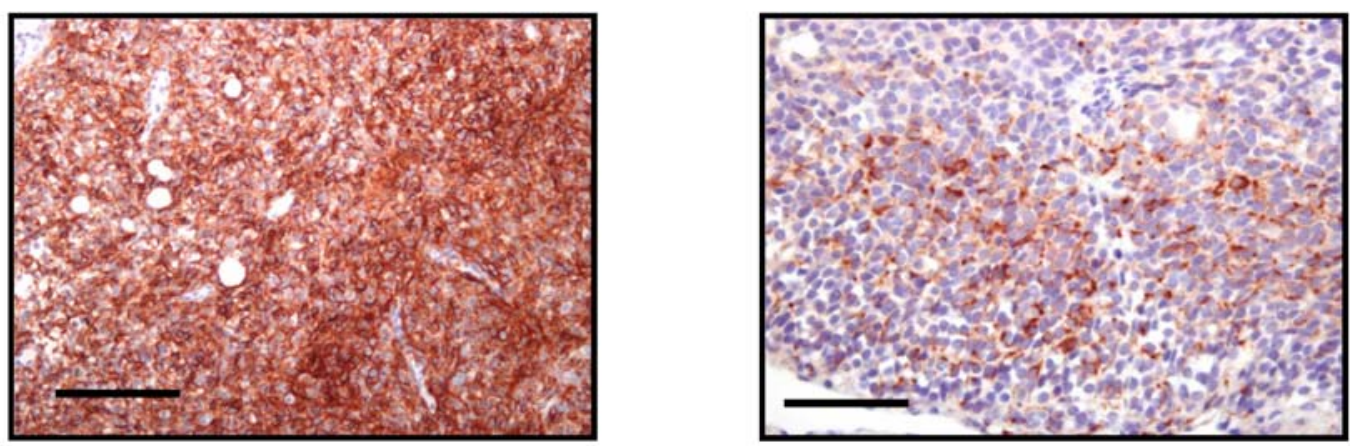

C
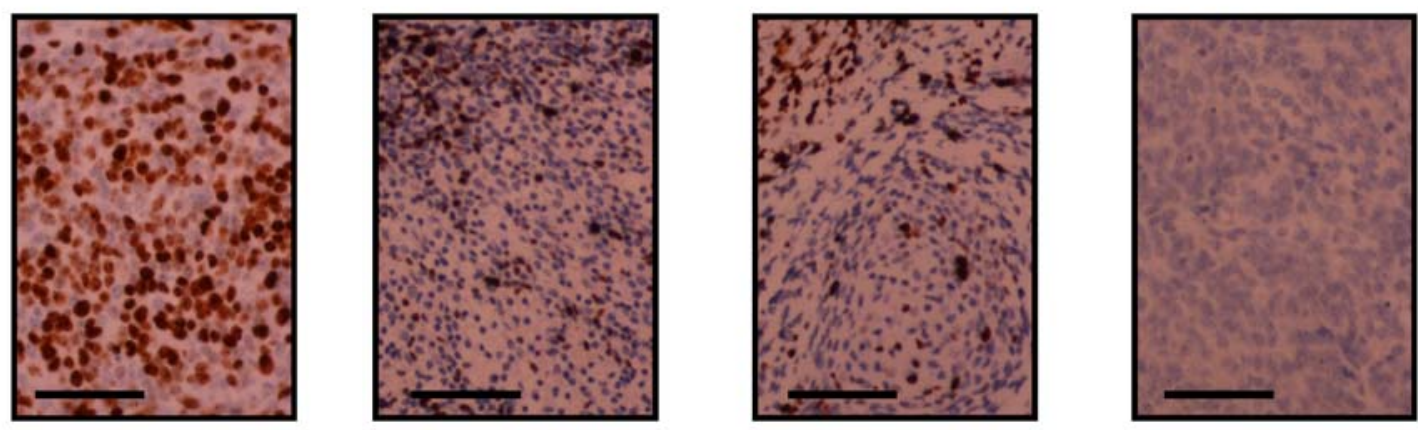

CHiPS A

CHiPS W

$\mathrm{H} 1$

NEG

Fig. 4. Analysis of the CHiPS A-derived tumour. (A) Expression of CD117 (or KIT, a germ cell tumour marker). (B) Expression of CD99 (a primitive neuroectodermal tumours and sex cord stromal tumours marker). (C) Increased proliferation in CHiPS A-derived tumour, as compared to CHiPS W- and H1-derived teratomas, indicated by Ki-67 staining. NEG-negative control with CHiPS A-derived tumour. Scale bar $=100 \mu \mathrm{m}$.

expression of exogenous OCT3/4 and NANOG in the CHiPS A line, along with endogenous genes (Fig. 2D). At the same time low levels of endogenous NANOG expression in CHiPS A line, despite complete promoter demethylation suggest other mechanisms blocking gene expression.

\section{Differentiation potential of CHiPS A}

The CHiPS A line, despite its ES-like morphology, failed to differentiate in vitro (Fig. 3A). During differentiation via embryoid bodies (EBs), in contrast to the CHiPS W line and the control hESC H1 line, EBs of CHiPS A dissociated over time (Fig. 3A). We also tried to direct differentiation of CHiPS A under adherent conditions using $10 \mu \mathrm{M}$ all-trans retinoic acid or to induce differentiation on a Matrigel-coated dish by bFGF withdrawal. However, we were unable to obtain mature EBs and cells ultimately dissociated over time (data not shown). To investigate the differentiation commitment to the three embryonic germ layers, we analysed the acquired expression of
FOXA2 (endoderm), MSI1 (ectoderm), and Brachyury (mesoderm) marker genes within the EBs of CHiPS A and CHiPS W from day 0 to day 8 (Fig. 3B). We observed the expected change in all the markers analysed in the CHiPS $\mathrm{W}$ and hESC H1 lines, indicating proper differentiation commitment. However, none of the markers increased with time in the CHiPS A line (Fig. 3B). We decided to verify whether this disability regarding in vitro differentiation extended into a defect in an in vivo teratoma formation assay. The histological examination showed that the CHiPS A cells formed invasive (multiple infiltrations into the surrounding tissue, lack of defined borders) germ celllike tumours when injected into NOD-SCID mice (Fig. 3C). In the same assay, the CHiPS W cells formed benign teratomas, as expected (Fig. 3C). To confirm the germ cell-like nature of the CHiPS A tumour, we also verified the expression of known seminoma markers DAZL, GDF3, $K I T$, and STELLAR, as well as the pluripotency markers NANOG, OCT3/4, and SOX2 (Ezeh et al., 2005; Gopalan et al., 2009) (Fig. 3D). We observed strong endogenous 
A
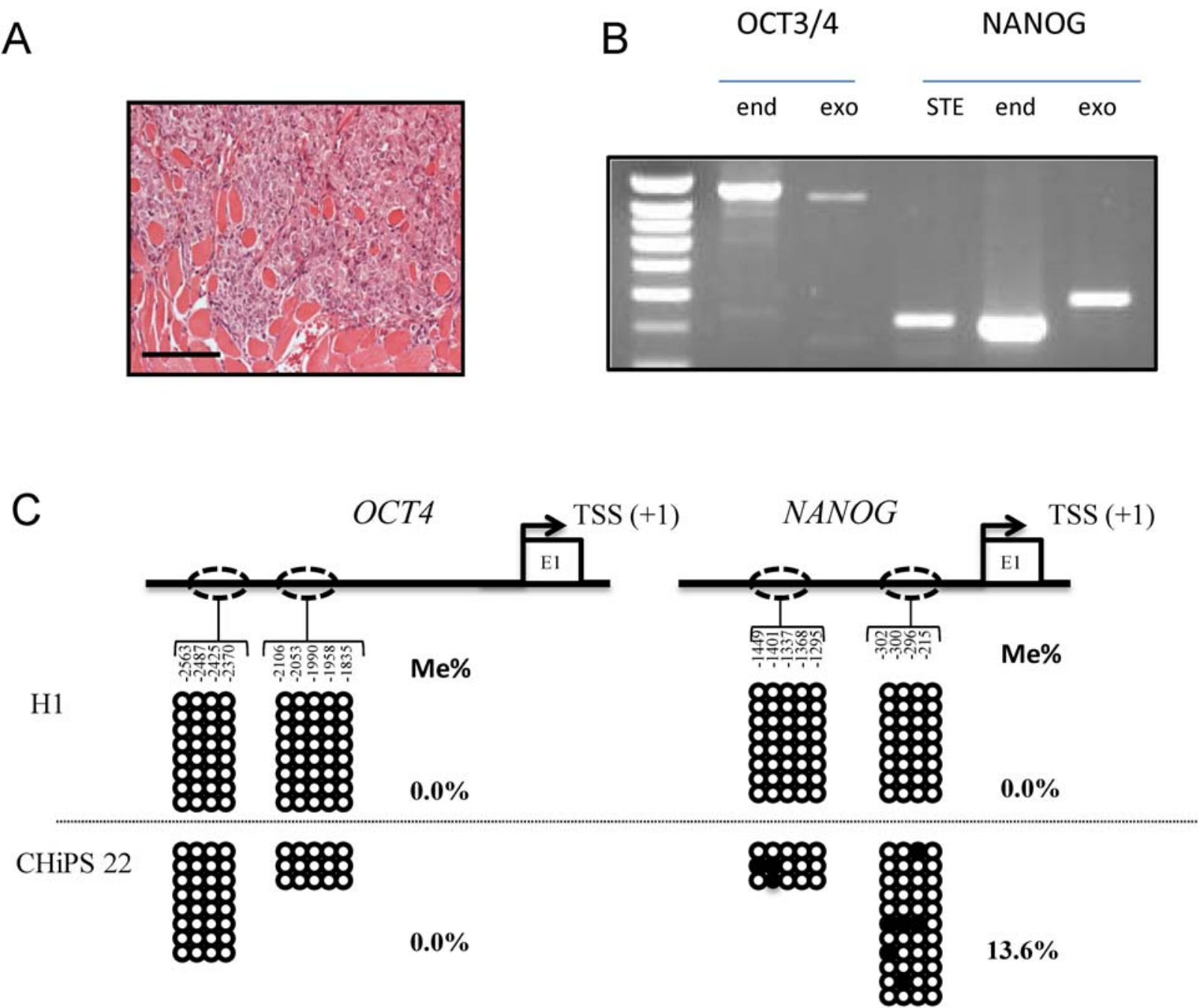

Fig. 5. Characterisation of CHiPS 22 line. (A) Haematoxylin and eosin staining of germ cell-like tumour derived from CHiPS 22 cells. Scale bar $=100 \mu \mathrm{m}$. (B) Expression of endogenous and exogenous OCT3/4 and NANOG in CHiPS 22 line by RT-PCR. Exogenous NANOG is expressed from two constructs, indicated by NANOG exo and STE (Stemcca). (C) Bisulphite genomic sequencing of OCT4 and NANOG promoters in CHiPS 22 and H1 lines. Each row represents an individual sequencing reaction for a given amplicon. Open and filled circles equal unmethylated and methylated CpGs dinucleotides, respectively. Percentage of methylation for each cell line is shown on the right.

and exogenous NANOG expression as well as GDF3 and STELLAR. DAZL and KIT were weakly expressed (Fig. 3D). However, KIT gave a very strong signal in the immunohistochemical assessment of the CHIPS A-derived tumor (Fig. 4A) as well as CD99, a known marker of primitive neuroectodermal and sex cord stromal tumours (Fig. 4B). In line with commonly increased proliferation in tumours (Soini et al., 1998), the CHiPS A-derived tumours showed a higher proliferative index compared to the CHiPS W- and H1-derived teratomas (Fig. 4C).

To investigate whether priming the cells with NANOG could have activated the carcinogenic program during reprogramming, regardless of the choice of other reprogramming genes, we repeated human fibroblast reprogramming, first with NANOG and then with the set of four Yamanaka reprogramming factors (OCT3/4, SOX2, $M Y C, K L F 4)$ expressed from one polycistronic vector (Sommer et al., 2009). The resulting iPSC line, the CHiPS 22 , also failed to differentiate in vitro. Importantly, in the teratoma formation assay, the CHiPS 22 cells gave rise to germ cell-like tumours, as did the CHiPS A cells (Fig. 5A). Semi-quantitative RT-PCR analysis of pluripotency gene expression showed that similarly to the CHiPS A line, transgenes for OCT3/4 and NANOG were not silenced, however, the relative quantities of the endogenous versus exogenous transcripts resembled those of the CHiPS W (Fig. 5B). Similar to the CHiPS W and by contrast to the CHiPS A, the OCT3/4 promoter of the CHiPS 22 was found hypomethylated (Fig. 5C). Therefore, we conclude that priming cells with NANOG before complete reprogramming might result in a germ cell-like tumour phenotype in vivo, regardless of the reprogramming factors used.

\section{Molecular characterisation}

It has been previously demonstrated that genomic abnormalities in hESC might lead to neoplastic progression (Werbowetski-Ogilvie et al., 2009). To investigate the 
A

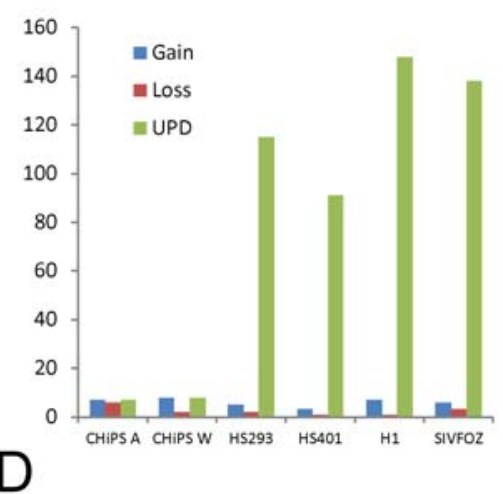

CHIPS A

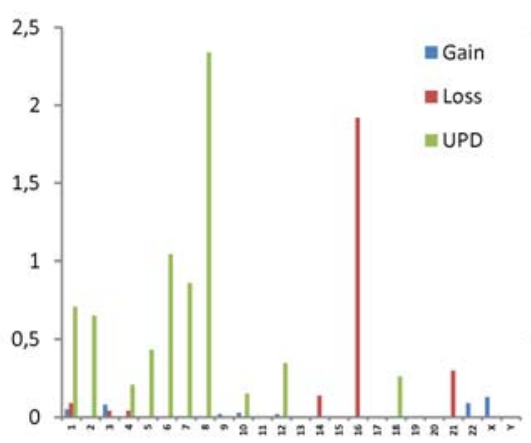

$E$

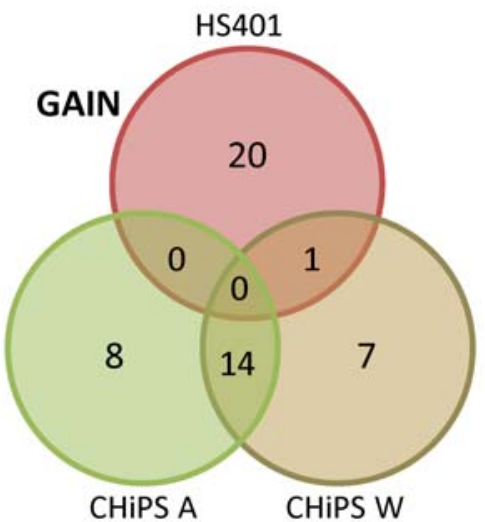

B

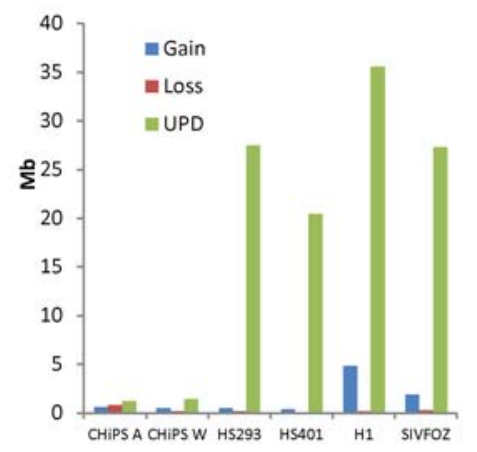

C

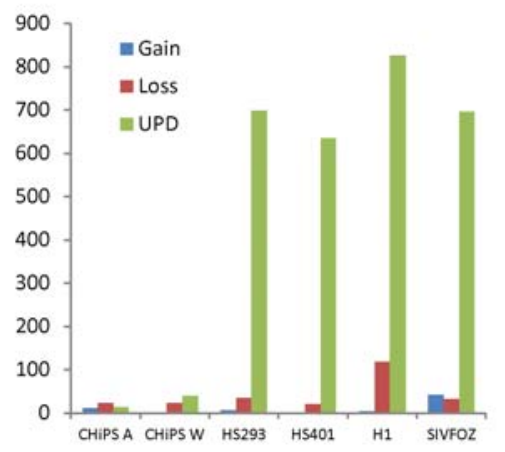

CHiPS W

HS401
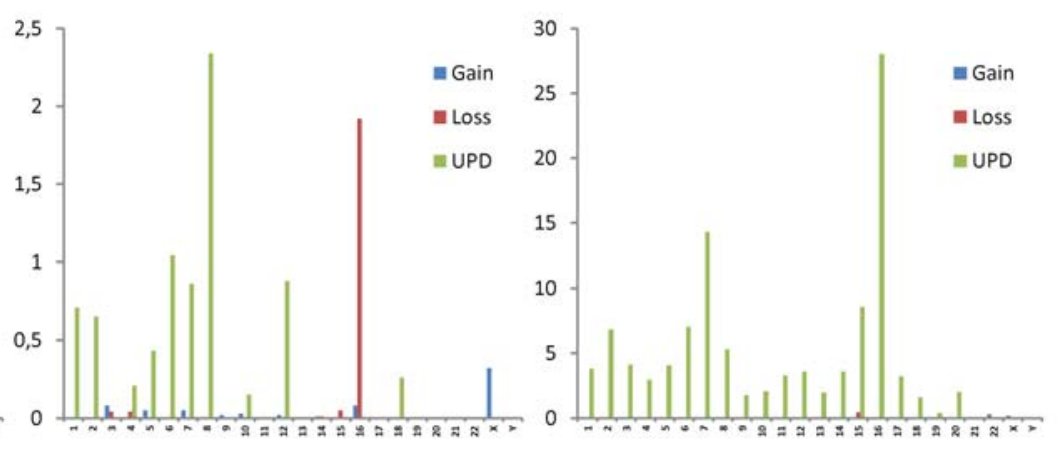

Fig. 6. Chromosomal variations in CHiPS A and CHiPS W lines. (A) Total number of variations, (B) genomic coverage of the variations and (C) total number of mutated genes. H1, HS293, HS401, SVF02 - human embryonic stem cell lines, HFF - human feeder fibroblasts. (D) Per chromosome coverage of genomic variations and (E) the number of genes in either deleted, duplicated or UPDs (uniparental disomies) regions in CHiPS A, CHiPS W and ES401 lines.

origin of the oncogenic potential of the CHiPS A line, array comparative genomic hybridisation (aCGH) was performed to evaluate the presence of genomic signatures. We compared the CHiPS A and CHiPS W lines with four hESC lines. This revealed some chromosomal variations, which were not detected previously with $G$ banding. Surprisingly, the total observed abnormalities were minor, compared to the ESC lines (Fig. 6A,B). Detailed analysis of each chromosome showed that the gains and losses were mainly concentrated in chromosomes 1, 3, 14, 16, 21, 22, and X for CHiPS A and 3, 16, and X for CHiPS W
(Fig. 6D). There were also multiple uniparental disomies affecting chromosomes $1,2,4,5,6,7,8,9,10,12$, and 18 in both lines in the same manner, suggesting a parental origin. Surprisingly, thorough examination revealed only a few genes present in the affected regions (Fig. 6C). Of these, 26 differed between the CHiPS A and the CHiPS W lines, 10 in the deleted regions and 16 in duplicated regions (Fig. 6E). Those genes were CHiPS A-specific, since they were also absent, apart from the olfactory receptor OR11H12, from the mutated regions of the control hESC line (HS401) (Table 2). Unexpectedly, the genes did not 
A
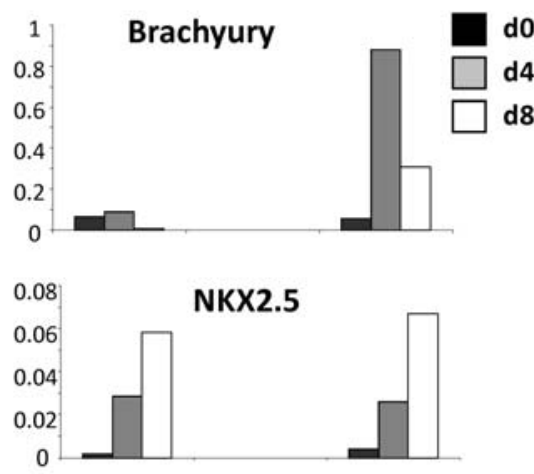

H1 CHiPS A CHiPS W

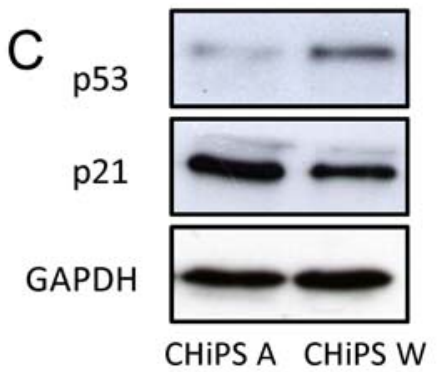

B

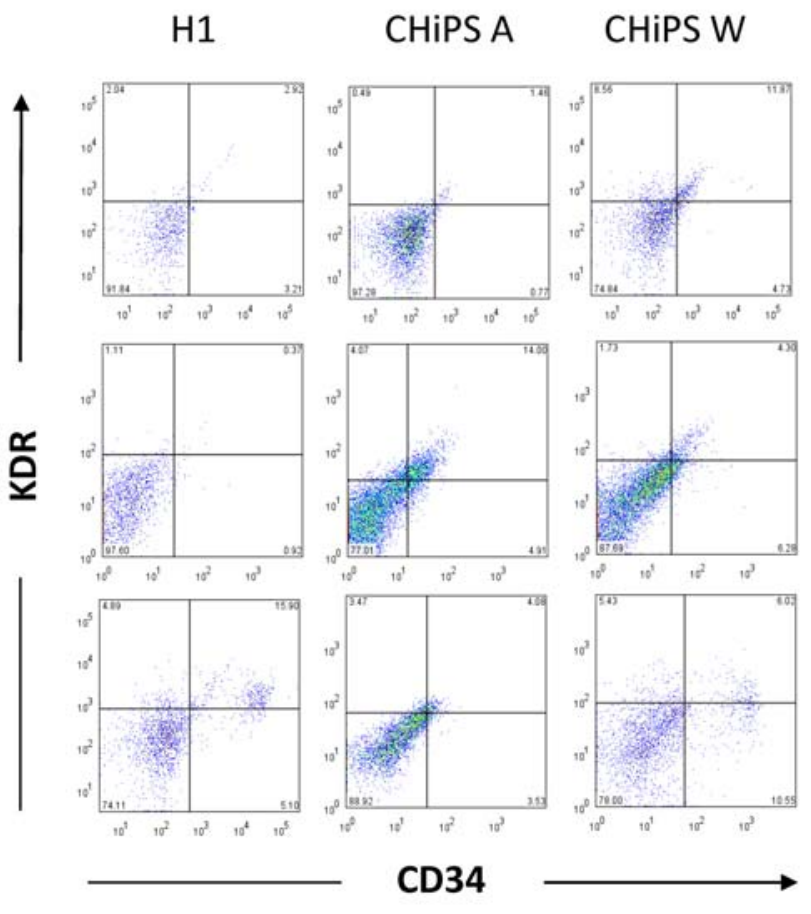

do

d4

d8

Fig. 7. Analysis of cardiac and haematopoietic differentiation, as well as p53 and p21 expression in CHiPS A and CHiPS W lines. (A) Differential quantitative expression of cardiac markers Brachyury and NKX2.5 at day 0, 4 and 8 of cardiac differentiation in CHiPS A, CHiPS W and H1 lines. (B) FACS analysis of the expression of the haematopoietic markers KDR and CD34 at day 0, 4 and 8 of haematopoietic differentiation. (C) Protein levels of p53 and p21 in CHiPS A and CHiPS W assessed by western blot, GAPDH - loading control.

include any tumour suppressor genes or oncogenes, nor did they encompass any known pluripotency genes (Table 2). The gene ontology analysis performed for three classes (Gene Ontology Molecular Function (GOMF), Biological Processes (GOBP) and Kegg pathways) showed multiple differences between the two lines, as summarised in Table 3. Of particular interest were potential defects in the cardiac and haematopoietic differentiation pathways in the CHiPS A line, as also revealed in the comparative pathway analysis between the CHiPS A and HS401 lines (Table 4).

To evaluate the prognostic values of aCGH analysis, we investigated whether the cells were capable of cardiac and directed haematopoietic differentiation in vitro, via embryoid body formation. In line with the aCGH data, quantitative analysis of the expression of the TBX1/ Brachyury, a major regulator of cardiac mesoderm formation, and NKX2-5, a cardiopoietic marker, revealed their absence from the CHiPS A line during in vitro cardiac differentiation (Fig. 7A). Further differentiation led to beating cardiomyocytes in case of the CHiPS W (Chicha et al., 2011), but not in the CHiPS A, which failed to differentiate and dissociated over time. It has been previously shown that the CHiPS W line is capable of undergoing haematopoietic differentiation (Chicha et al., 2011). FACS analysis of differentiating embryoid bodies from the CHiPS $\mathrm{W}$ and the hESC H1 line showed an increase in the $\mathrm{CD} 34+/ \mathrm{KDR}+$ cell population with differentiation time; however, these vascular endothelial surface antigen markers were absent from the CHiPS A line (Fig. 7B).

The TP53 (p53) tumour suppressor is an established factor connecting tumourigenesis and reprogramming to pluripotency, (reviewed in Tapia and Scholer, 2010). Therefore, we analysed p53 and p 21 protein levels in the CHiPS A and CHiPS W cell lines. In the normal, pluripotent CHiPS W cell line, the proportion of p53 to p 21 was higher than in the tumourigenic CHiPS A cell line (Fig. 7C).

\section{Discussion}

Embryonic stem cells (ESCs) and induced pluripotent stem cells (iPSCs) offer great therapeutic promise. However, their potential tumourigenicity must be addressed before they can be taken into the clinic. In 1997, Bonnet and Dick proposed the new concept of cancer stem cells (CSCs) (Bonnet and Dick, 1997), a small selected population within a tumour, characterised by stem-like genomic and epigenetic signatures, including for instance OCT3/4 and NANOG expression. It is still unclear where CSCs originate, but reprogramming and carcinogenesis share many common features. For instance, deactivation of the antitumour p53-p21 barrier increases the yield of iPSC generation (Hong et al., 2009). For the therapeutic use of stem cells in the future, it is of crucial importance to discriminate between normal and cancer stem cells; however, proper cellular models are still missing. 
Table 2. List of the genes in the affected regions characteristic for a given line.

\begin{tabular}{|c|c|c|}
\hline CHiPS A but not CHiPS W & CHiPS W but not CHiPS A & CHiPS A but not HS401 \\
\hline WDR63 & ZDHHC11 & WDR63 \\
\hline MCOLN3 & BRD9 & MCOLN3 \\
\hline SYDE2 & FAM115A & SYDE2 \\
\hline GJA5 & OR2F2 & GJA5 \\
\hline GJA8 & OR2F1 & GJA8 \\
\hline GPR89B & OR2Q1P & GPR89B \\
\hline NR5A2 & PAOX & NR5A2 \\
\hline FAM58B & PCDH11X & FAM58B \\
\hline GATA2 & & GATA2 \\
\hline OR11H12 & & C3orf27 \\
\hline NF1L6 & & RPN1 \\
\hline NF1L4 & & TMED10P2 \\
\hline TMPRSS15 & & MIR720 \\
\hline PPIAL3 & & UGT2B28 \\
\hline EFCAB6 & & RBPJP6 \\
\hline SULT4A1 & & ATP5A1P6 \\
\hline PNPLA5 & & MTG1 \\
\hline \multirow[t]{16}{*}{ HMGN2L9 } & & CYP2E1 \\
\hline & & SPRN \\
\hline & & STX2 \\
\hline & & RAN \\
\hline & & NF1L6 \\
\hline & & NF1L4 \\
\hline & & TMPRSS15 \\
\hline & & PPIAL3 \\
\hline & & EFCAB6 \\
\hline & & SULT4A1 \\
\hline & & PNPLA5 \\
\hline & & HMGN2L9 \\
\hline & & ZNF81 \\
\hline & & ZNF182 \\
\hline & & ZNF630 \\
\hline & & SPACA5 \\
\hline
\end{tabular}

In the present work, we generated two reprogrammed cell lines from human dermal fibroblasts. The first line, CHiPS W, had a differentiation potential comparable to a normal human ESC line while the other, CHiPS A, failed to undergo in vitro and in vivo differentiation and induced germ cell-like tumours, confirmed by marker expression analysis. We sought to characterise genomic variations at the genome-wide level and to associate these with the behaviour of the cell lines used in this study. G-banding was used to assess variations at the macroscopic level and, subsequently, Affymetrix SNP6.0 arrays were run to detect copy number variations (CNVs) at kb resolution. On this scale, no variations were detected that could be associated with tumour suppressor or oncogenes. Although a number of common structural variants, like InDels or short inversions, escape the methods used in this study, CNVs represent the predominant form of variation, and have the highest de novo mutation rate in the genome. Our results suggest that the role of genomic variations in determining the tumourigenic phenotype might not be a major one, which implies epigenetic-level mechanisms leading to tumourigenic characteristics. However, considering multiple reports of iPSCs genomic instability (Gore et al., 2011; Hussein et al., 2011; Laurent et al., 2011; Mayshar et al., 2010; Pasi et al., 2011), it remains an open question whether the genomes of the derived cell lines remain stable over time.

The p53 tumour suppressor plays a pivotal role in cancer prevention (reviewed in Molchadsky et al., 2010) but also, as recently demonstrated, in reprogramming somatic cells to pluripotency (Hong et al., 2009; Kawamura et al., 2009; Utikal et al., 2009). Recent microRNA profiling analysis of iPSCs and cancer cell lines also demonstrated differences in the status of the p53 network in these two cellular populations (Neveu et al., 2010). Morigucchi et al. have proposed that a higher ratio of p53 to 21 might be responsible for shifting the balance from stemness to tumourigenicity in iPSCs (Moriguchi et al., 
Table 3. Process affected in CHiPS A as compared to CHiPS W.

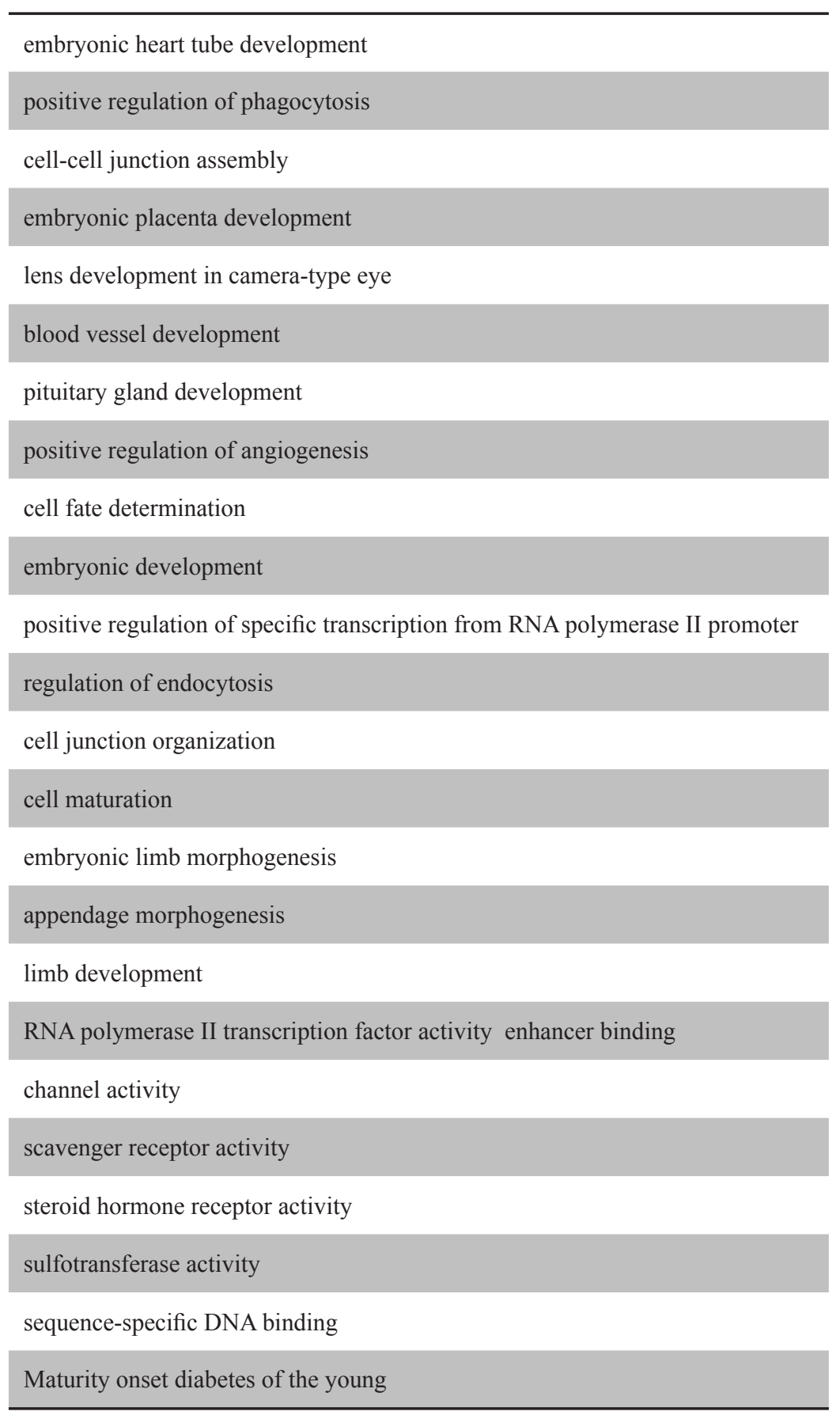

2010). Our results do not support the model proposed by Moriguchi, as the ratio of p53 to p21 was lower in the tumourigenic CHiPS A line than in the CHiPS W line. The lack of differentiation within the CHiPS A-derived teratomas resembles tumours derived with p53-deficient iPSCs, using the four Yamanaka factors (Hong et al., 2009). Accordingly, we observed lower $\mathrm{p} 53$ protein expression in our tumourigenic line CHiPS A, compared to the CHiPS $\mathrm{W}$. This is in accordance with the crucial role of p53 in limiting tumourigenicity. At the same time, the p53/p21 ratio in the CHiPS 22 line, contrary to the CHiPS A, was similar to the CHiPS W, suggesting that other mechanisms are involved (data not shown).

At this stage of investigation, we can only speculate on the possible molecular mechanism leading to the observed phenotype. Reprogramming of somatic cells into the CHiPS A and CHiPS W lines was achieved by initial pretransduction with NANOG. A recent report by Tiemann et al. shows the importance of the stoichiometry of RGs in the reprogramming process (Tiemann et al., 2011). It remains to be determined if the pre-selection with puromycin in the CHiPS W line significantly changed the final stoichiometry of the RGs, allowing better reprogramming into a stable pluripotent state as compared to the CHiPS A and CHiPS22 lines. Considering the Tiemann et al. data, it is plausible that a distinct stoichiometry of RGs controls not only full reprogramming, but also the balance between the pluripotent and tumourigenic phenotypes.

Although NANOG is not considered to be cancer inducing, it might have pre-induced the cell to additional 
Table 4. Process affected in CHiPS A as compared to HS401.

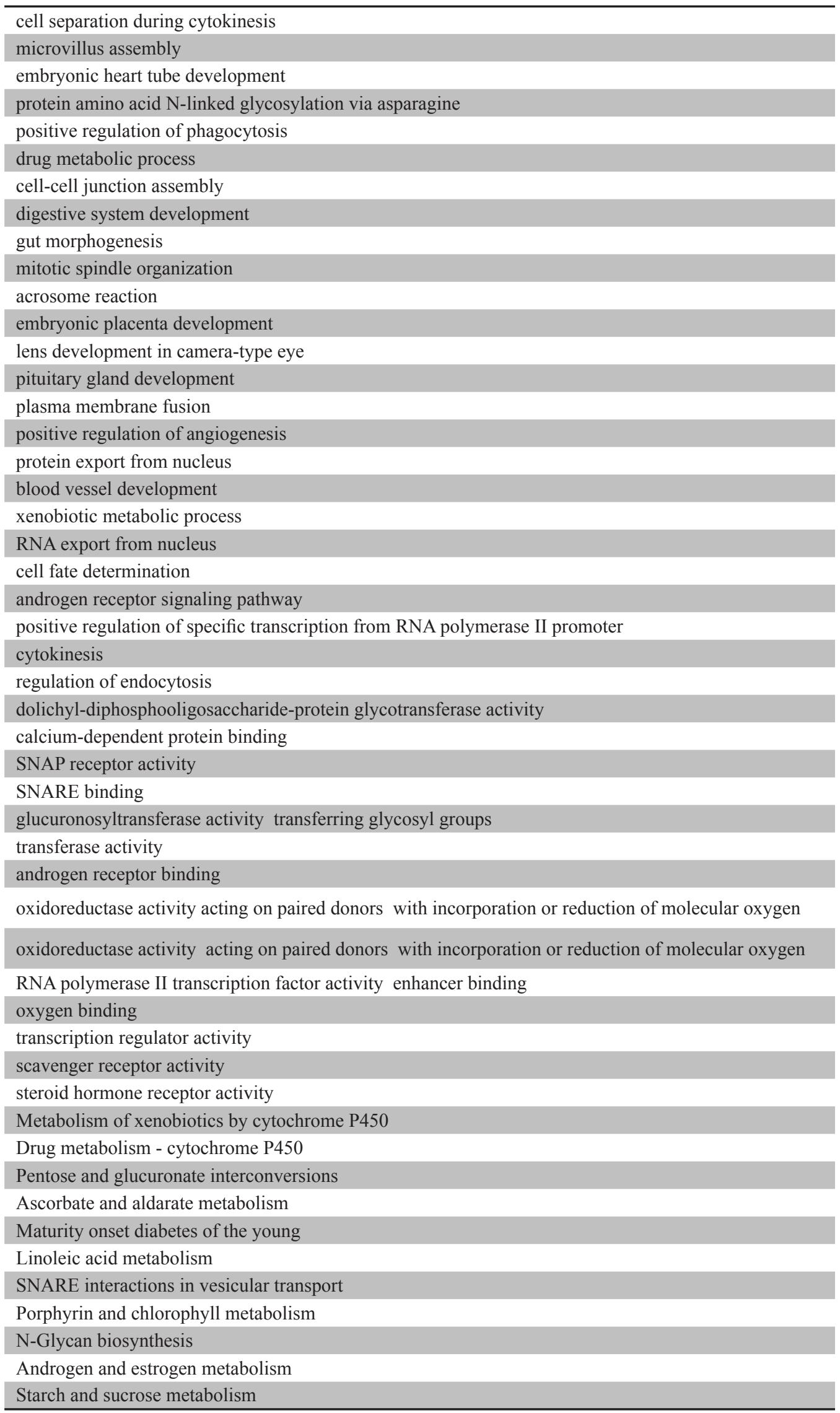


cancer pathway-activating changes. Considering that CHiPS 22, another iPSC line with similar characteristics, could be obtained using a different set of reprogramming factors but with the same pre-induction with NANOG, the molecular mechanism behind the process is probably NANOG-related. While it is known that NANOG expression suppresses differentiation in murine ESCs (Chambers et al., 2003), a recent loss-of-function analysis in cancer cell lines has demonstrated a role of NANOG in tumour development (Jeter et al., 2009). In addition, Lindgren et al. have shown that failed repression of Nanog in Pten null mouse ESCs leads to tumour initiation (Lindgren et al., 2011). In germ cell tumours and derived cell lines, methylation of CpGs in the NANOG promoter has been correlated with the differentiation state (Nettersheim et al., 2011). Consequently, the lack of silencing of endogenous and/or exogenous NANOG expression during the CHiPS A and the CHiPS 22 differentiation in vitro and in the tumours might be directly responsible for the observed phenotype. Whether pre-induction of fibroblasts with NANOG carried by excisable factors or other transient means would result in the same cellular phenotype remains to be determined.

We believe that the resulting phenotype is an outcome of complex and interrelated epigenetic changes. The role of NANOG seems to be crucial; however, CHiPS A and CHiPS 22 differ despite their similar phenotypes. For instance, the CHiPS A line lacks SOX2 expression. Nevertheless the re-introduction of SOX2 using a lentiviral vector did not rescue the phenotype and the new SOX2+ CHiPS A line still failed to differentiate (data not shown). Furthermore, the tumourigenic CHiPS 22 line expresses SOX2, which altogether suggests that the molecular mechanism is not SOX2-dependent. Similarly, the CHiPS A line, in contrast to the CHiPS 22, overexpresses OCT3/4 and, as previously demonstrated, ectopic expression of OCT3/4 might block progenitor differentiation and cause carcinogenesis (Hochedlinger et al., 2005). Likewise, human cancers often display altered expression of MYC, a proto-oncogene used here during the reprogramming of the CHiPS 22 line. It has also been demonstrated during reprogramming that the MYC oncogene leads to increased tumour transformation (Okita et al., 2007). However, the CHiPS A was reprogrammed with the Thomson set of reprogramming genes, and its MYC expression was barely stimulated (data not shown), indicating that MYC is not directly responsible for the resulting carcinogenic behaviour.

\section{Conclusion and Summary}

The present data highlight five major points: priming with NANOG before reprogramming of human somatic cells can generate cells with the characteristics of iPS cells; despite their expression of pluripotency markers, such cell lines may fail to differentiate; in vitro differentiation failure might translate into germ cell-like tumour induction in the in vivo differentiation assay; the tumourigenic iPSC line might be genetically stable which implicates the involvement of epigenetic mechanisms in the activation of the carcinogenic program; one of the plausible mechanisms of carcinogenic program induction may involve the p21/ p53 ratio.

Our results are the first describing iPSC lines that behave similarly to pluripotent cell lines in vitro but are unable to differentiate. These cells do however induce germ cell-like tumours in vivo. The tumourigenic character of the reprogrammed lines might result from epigenetic events that occurred during priming the cells with NANOG. It is therefore important to test derived iPSCs, not only at the molecular and cellular level, but also using an in vivo teratoma formation assay, which is essential in the assessment of the carcinogenic potential of the reprogrammed pluripotent stem cells. At the same time, we believe that our results might open new vistas in the area of stemness versus carcinogenesis, while the CHiPS A, CHiPS 22 and CHiPS W lines might serve as a model for comparing cellular signalling leading to normal and malignant conditions.

\section{Acknowledgements}

We would like to thank Sandrine Vianin for help with iPSC line derivation and technical support and Lasta Kocjancic-Curty for technical support. We are also grateful to Dr. Marie Cohen, Geneva University Hospital and Prof. Thanos Halazonetis, University of Geneva, for kindly sharing p53 and p21 antibodies, as well as Prof. Olivier Irion, Geneva University Hospitals for material support. This work was supported by the Swiss National Foundation (grant 310000-119938/1), the Roche Research Foundation, the Ernst \& Lucie Schmidheiny Foundation, the Geneva University Hospitals, Genico, and the Swedish Research Council.

\section{References}

Bettiol E, Clement S, Krause KH, Jaconi ME (2006) Embryonic and adult stem cell-derived cardiomyocytes: lessons from in vitro models. Rev Physiol Biochem Pharmacol 157: 1-30.

Blum B, Benvenisty N (2009) The tumorigenicity of diploid and aneuploid human pluripotent stem cells. Cell Cycle 8: 3822-3830.

Bomken S, Fiser K, Heidenreich O, Vormoor J (2010) Understanding the cancer stem cell. Br J Cancer 103: 439445 .

Bonnet D, Dick JE (1997) Human acute myeloid leukemia is organized as a hierarchy that originates from a primitive hematopoietic cell. Nat Med 3: 730-737.

Chambers I, Colby D, Robertson M, Nichols J, Lee S, Tweedie S, Smith A (2003) Functional expression cloning of nanog, a pluripotency sustaining factor in embryonic stem cells. Cell 113: 643-655.

Chicha L, Feki A, Boni A, Irion O, Hovatta O, Jaconi M (2011) Human pluripotent stem cells differentiated in fully defined medium generate hematopoietic CD34 and CD34 progenitors with distinct characteristics. PLoS One 6: e14733. 
Ezeh UI, Turek PJ, Reijo RA, Clark AT (2005) Human embryonic stem cell genes Oct4, Nanog, Stellar, and Gdf3 are expressed in both seminoma and breast carcinoma. Cancer 104: 2255-2265.

Freberg CT, Dahl JA, Timoskainen S, Collas P (2007) Epigenetic reprogramming of Oct4 and Nanog regulatory regions by embryonal carcinoma cell extract. Mol Biol Cell 18: 1543-1553.

Gopalan A, Dhall D, Olgac S, Fine SW, Korkola JE, Houldsworth J, Chaganti RS, Bosl GJ, Reuter VE, Tickoo SK (2009) Testicular mixed germ cell tumors: a morphological and immunohistochemical study using stem cell markers, Oct3/4, Sox 2 and Gdf3, with emphasis on morphologically difficult-to-classify areas. Mod Pathol 22: 1066-1074.

Gore A, Li Z, Fung HL, Young JE, Agarwal S, Antosiewicz-Bourget J, Canto I, Giorgetti A, Israel MA, Kiskinis E, Lee JH, Loh YH, Manos PD, Montserrat N, Panopoulos AD, Ruiz S, Wilbert ML, Yu J, Kirkness EF, Izpisua Belmonte JC, Rossi DJ, Thomson JA, Eggan K, Daley GQ, Goldstein LS, Zhang K (2011) Somatic coding mutations in human induced pluripotent stem cells. Nature 471: 63-67.

Guzman ML, Rossi RM, Karnischky L, Li X, Peterson DR, Howard DS, Jordan CT (2005) The sesquiterpene lactone parthenolide induces apoptosis of human acute myelogenous leukemia stem and progenitor cells. Blood 105: 4163-4169.

Hochedlinger K, Yamada Y, Beard C, Jaenisch R (2005) Ectopic expression of Oct-4 blocks progenitor-cell differentiation and causes dysplasia in epithelial tissues. Cell 121: 465-477.

Hong H, Takahashi K, Ichisaka T, Aoi T, Kanagawa O, Nakagawa M, Okita K, Yamanaka S (2009) Suppression of induced pluripotent stem cell generation by the p53-p21 pathway. Nature 460: 1132-1135.

Hovatta O, Jaconi M, Tohonen V, Bena F, Gimelli S, Bosman A, Holm F, Wyder S, Zdobnov EM, Irion O, Andrews PW, Antonarakis SE, Zucchelli M, Kere J, Feki A (2010) A teratocarcinoma-like human embryonic stem cell (hESC) line and four hESC lines reveal potentially oncogenic genomic changes. PLoS One 5: e10263.

Hussein SM, Batada NN, Vuoristo S, Ching RW, Autio R, Narva E, Ng S, Sourour M, Hamalainen R, Olsson C, Lundin K, Mikkola M, Trokovic R, Peitz M, Brustle O, Bazett-Jones DP, Alitalo K, Lahesmaa R, Nagy A, Otonkoski T (2011) Copy number variation and selection during reprogramming to pluripotency. Nature 471: 58-62.

Inunza J, Gertow K, Strömberg MA, Matilainen E, Blennow E, Skottman H, Wolbank S, Ahrlund-Richter L, Hovatta O (2005) Derivation of human embryonic stem cell lines in serum replacement medium using postnatal human fibroblasts as feeder cells. Stem Cells 23: 544-549.

Jeter CR, Badeaux M, Choy G, Chandra D, Patrawala L, Liu C, Calhoun-Davis T, Zaehres H, Daley GQ, Tang DG (2009) Functional evidence that the self-renewal gene Nanog regulates human tumor development. Stem Cells 27: 993-1005.

Kawamura T, Suzuki J, Wang YV, Menendez S, Morera LB, Raya A, Wahl GM, Belmonte JC (2009)
Linking the p53 tumour suppressor pathway to somatic cell reprogramming. Nature 460: 1140-1144.

Laurent LC, Ulitsky I, Slavin I, Tran H, Schork A, Morey R, Lynch C, Harness JV, Lee S, Barrero MJ, Ku S, Martynova M, Semechkin R, Galat V, Gottesfeld J, Izpisua Belmonte JC, Murry C, Keirstead HS, Park HS, Schmidt U, Laslett AL, Muller FJ, Nievergelt CM, Shamir $\mathrm{R}$, Loring JF (2011) Dynamic changes in the copy number of pluripotency and cell proliferation genes in human ESCs and IPSCs during reprogramming and time in culture. Cell Stem Cell 8: 106-118.

Lindgren AG, Natsuhara K, Tian E, Vincent JJ, Li X, Jiao J, Wu H, Banerjee U, Clark AT (2011) Loss of PTEN causes tumor initiation following differentiation of murine pluripotent stem cells due to failed repression of Nanog. PLoS One 6: e16478.

Maherali N, Ahfeldt T, Rigamonti A, Utikal J, Cowan C, Hochedlinger K (2008) A high-efficiency system for the generation and study of human induced pluripotent stem cells. Cell Stem Cell 3: 340-345.

Mayshar Y, Ben-David U, Lavon N, Biancotti JC, Yakir B, Clark AT, Plath K, Lowry WE, Benvenisty N (2010) Identification and classification of chromosomal aberrations in human induced pluripotent stem cells. Cell Stem Cell 7: 521-531.

Molchadsky A, Rivlin N, Brosh R, Rotter V, Sarig $R$ (2010) P53 is balancing development, differentiation and de-differentiation to assure cancer prevention. Carcinogenesis 31: 1501-1508.

Moriguchi H, Chung RT, Sato C (2010) Tumorigenicity of human induced pluripotent stem cells depends on the balance of gene expression between p21 and p53. Hepatology 51: 1088-1089.

Nettersheim D, Biermann K, Gillis AJ, Steger K, Looijenga LH, Schorle H (2011) Nanog promoter methylation and expression correlation during normal and malignant human germ cell development. Epigenetics 6: 114-122.

Neveu P, Kye MJ, Qi S, Buchholz DE, Clegg DO, Sahin M, Park IH, Kim KS, Daley GQ, Kornblum HI, Shraiman BI, Kosik KS (2010) Microrna profiling reveals two distinct p53-related human pluripotent stem cell states. Cell Stem Cell 7: 671-681.

Okita K, Ichisaka T, Yamanaka S (2007) Generation of germline-competent induced pluripotent stem cells. Nature 448: 313-317.

Pasi CE, Dereli-Oz A, Negrini S, Friedli M, Fragola G, Lombardo A, Van Houwe G, Naldini L, Casola S, Testa G, Trono D, Pelicci PG, Halazonetis TD (2011) Genomic instability in induced stem cells. Cell Death Differ 18: 745-753.

Peirson SN, Butler JN, Foster RG (2003) Experimental validation of novel and conventional approaches to quantitative real-time PCR data analysis. Nucleic Acids Res 31: e73.

Silva J, Chambers I, Pollard S, Smith A (2006) Nanog promotes transfer of pluripotency after cell fusion. Nature 441: 997-1001.

Soini Y, Paakko P, Lehto VP (1998) Histopathological evaluation of apoptosis in cancer. Am J Pathol 153: 10411053. 
Sommer CA, Stadtfeld M, Murphy GJ, Hochedlinger K, Kotton DN, Mostoslavsky G (2009) Induced pluripotent stem cell generation using a single lentiviral stem cell cassette. Stem Cells 27: 543-549.

Stadtfeld M, Hochedlinger K (2010) Induced pluripotency: history, mechanisms, and applications. Genes Dev 24: 2239-2263.

Ström S, Holm F, Bergström R, Strömberg AM, Hovatta O (2010) Derivation of 30 human embryonic stem cell lines - improving the quality. In Vitro Cell Dev Biol Anim 46: $337-344$.

Takahashi K, Tanabe K, Ohnuki M, Narita M, Ichisaka T, Tomoda K, Yamanaka S (2007) Induction of pluripotent stem cells from adult human fibroblasts by defined factors. Cell 131: 861-872.

Tapia N, Scholer HR (2010) P53 connects tumorigenesis and reprogramming to pluripotency. J Exp Med 207: 2045 2048.

Tiemann U, Sgodda M, Warlich E, Ballmaier M, Scholer HR, Schambach A, Cantz T (2011) Optimal reprogramming factor stoichiometry increases colony numbers and affects molecular characteristics of murine induced pluripotent stem cells. Cytometry A 79: 426-435.

Tysnes BB (2010) Tumor-initiating and -propagating cells: cells that we would like to identify and control. Neoplasia 12: 506-515.

Unger C, Gao S, Cohen M, Jaconi M, Bergstrom R, Holm F, Galan A, Sanchez E, Irion O, Dubuisson JB, Giry-Laterriere M, Salmon P, Simon C, Hovatta O, Feki A (2009) Immortalized human skin fibroblast feeder cells support growth and maintenance of both human embryonic and induced pluripotent stem cells. Hum Reprod 24: $2567-$ 2581.

Utikal J, Polo JM, Stadtfeld M, Maherali N, Kulalert W, Walsh RM, Khalil A, Rheinwald JG, Hochedlinger
K (2009) Immortalization eliminates a roadblock during cellular reprogramming into IPS cells. Nature 460: 11451148.

Werbowetski-Ogilvie TE, Bosse M, Stewart M, Schnerch A, Ramos-Mejia V, Rouleau A, Wynder T, Smith MJ, Dingwall S, Carter T, Williams C, Harris C, Dolling J, Wynder C, Boreham D, Bhatia M (2009) Characterization of human embryonic stem cells with features of neoplastic progression. Nat Biotechnol 27: 91-97.

Yilmaz OH, Valdez R, Theisen BK, Guo W, Ferguson DO, Wu H, Morrison SJ (2006) Pten dependence distinguishes haematopoietic stem cells from leukaemiainitiating cells. Nature 441: 475-482.

Yu J, Vodyanik MA, Smuga-Otto K, AntosiewiczBourget J, Frane JL, Tian S, Nie J, Jonsdottir GA, Ruotti V, Stewart R, Slukvin, II, Thomson JA (2007) Induced pluripotent stem cell lines derived from human somatic cells. Science 318: 1917-1920.

\section{Discussion with Reviewers}

Reviewer I: Do the authors think that more epigenetic studies should be done?

Authors: Considering the increasing amount of data connecting tumourigenicity and epigenetic mechanisms it would be very interesting to investigate not only the genomics but also epigenomics of the generated lines. This would be particularly relevant in the context of NANOG but also the genes already known to participate in the processes of reprogramming. We believe that this kind of investigation if applied on the parental fibroblasts together with the "normal" and "tumourigenic" lines that we have generated, could provide interesting data on the mechanisms leading to malignancy. 